粉圧回復係数の推定など理論的基礎づけの興味ある分

野が残されているといえよう.

再循環の構想を最終的に評価するためには、上下動, 縦摇れに対する安定性，実用的にはフレキシブル・ス カートとの適合など今後解決すべき問題も大きいと思 われる.
文献

1) The Cockerell Papers, Part V.: Flight (1963-6-25) p. 12.

2) Horcomse B.F.: Materials and Fabrication Techniques in Air Cushion Vehicles, Proc. Nat. Meet. Hydrofoils \& ACV (1962-9) p. 106.

3) CossarrT, K. R.: A Recirculation Concept, Proc. Nat. Meet. Hydrofoils \& ACV (1962-9) p. 81.

4) Nishi A. \& SAWADA T. Ground Effect of Recirculating Jet, Bullentin Univ. Osaka Pref. Ser. A. Vol. 12, No. 2 (1964) p. 1.

\title{
上下運動を行なう地面効果機の底面圧力に関する研究*
}

$$
\text { 三ッ矢 明**.松 岡健 次** }
$$

\section{A Study on Base Pressure of Ground Effect Machine in Heaveing Motion}

Akira Mrtsuya and Kenji Matsuoka

\begin{abstract}
The theory of the dynamics of a peripheral jet GEM in heave is presented. Flow is assumed inviscid and incompressible, and the flow patterns under the bottom of GEM are classified into such types as balanced, underfed, and overfed regimes. In each regime, momentum bálances under the bottom are considered, and Stanton JoNes" "exponential theory" is applied. The present theory shows reasonable agreement with the experiments using a two-dimensional quasi-static model.
\end{abstract}

\section{1. 緒言}

周辺噴流型地面勃果機の上下運動については，古く は TULIN ${ }^{11}$, EAMES $^{2)}$ の論文があるが, とれらで重要 な点は，上下運動する GEM のジェットの流れの状態 をつぎの三種一平衡状態，アンダフェッド状態，オ一 バフェッド状態に分類して論じたととと考える，その 後に発表された文献は，いずれもこれらの仮定を用い ている.

DUKES と HARGRAVES ${ }^{3)}$ も同様な仮定のもとに， 流れは理想流体とし，GEM 底面下の水平方向の運動 量の鈞り合い加ら. GEM の上下運動のバネ定数，減 衰係数を求め，実験之比较しているが，ジェット効率 や，降下運動時の運動量の釣り合いについて問題点も ある。

筆者らは，DUKES らの考え方に多少の修正を行な った理墖を導き，さらに準静的な状態での上記の仮定 の努当性を検討するため，とれらの状態を静的に模擬 できるような装晸により実験し，理諭と比較した。

\footnotetext{
*昭和 42 年 2 月 20 日 GEM シンポジウムにおいて器表，昭和 42 年 10 月 3 日原䔉受理

"* 大服府立大学工学部
}

2. 記 号

by: ノズル幅

h: 深上高

$\bar{h}: h / b_{j}$

$\dot{h}:$ 上下運動の速度（上昇を正にとる）

$\bar{h}: \dot{h} / v_{\infty}$

$J: シ ゙ ェ ッ ト$ 運動量流れ

$\bar{J}=J / J_{\infty}$

l: ノズル周長

$m:$ 䁈量流富

$p_{B}$ : 底面圧力

$\bar{p}_{B}: p_{B} / p_{t j}$

$p_{i j}: シ ゙ ェ ッ ト$ 総圧

$q:$ ノズル出口の平均動压

$S_{B}:$ 医面積

$S_{j}:$ ノズル出口の断面積

$v$ : 流速

$x$ : 底面中心より外方向へ測った距離

$\beta$ : ノズル傾角 (内向きを正)

$\eta_{I}: シ ゙ x ッ ト$ 効率

$\rho:$ 空気密度

$\zeta:$ 損失係数

添え字
$B$ : 底面
$b$ : 平衡状態
0: オーバフェッド状態
u: アンダフェッド状態
1: ノズル・ジェット下流
2: 底面下八流入または流出する流れ
自由流 


\section{3. 理 論}

GEM の上下運動を取り扱う場合，一般に行なわれ るように平衡状龍, アンダフェッド状態,オーバフェ ッド状態に分けて考える，流れは非粘性，韭王縮とす ろ. 各状態は準静的であると考えて, 水平方向の運動 量流れの釣り合いから関係式を導く.

（1）平衡状態 GEM が上下運動を行なわず，水 平に浮上している場合の状態である. ジェット・カー テンは地面に接して外方へ流机去り, 地面から離れて 浮き上がって流れたり，底面下へ流入したりはしな い.

第 1 図(1)において，水平方向の運動量流れの釣り

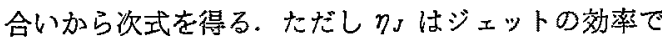
ある。

$$
h p_{B b}=\eta_{J}\left(J_{b} \sin \beta+J_{b_{1}}\right)
$$

ノズ出口およびジェット流れの下流においてジッッ ト運動量流れはそれぞれ

$$
\begin{aligned}
& J_{b}=m_{b} v_{b} \\
& J_{b_{1}}=m_{b_{1}} v_{b_{1}}
\end{aligned}
$$

平衡状態ではジェット流れは分流を生じないから

$$
m_{b 1}=m_{b}
$$

またノズル無限下流の $v_{b_{1}}$ は

$$
v_{b_{1}}=v_{\infty}
$$

となるから

$$
J_{b_{1}}=m_{b} \gamma_{\infty}
$$

となり(1)式は

$$
h p_{B b}=\eta_{J} J_{b}\left(\frac{v_{\infty}}{v_{b}}+\sin \beta\right)
$$

ここで $J_{b}$ に指数理論(4)を適用すると $J_{b}$ は

$$
\begin{aligned}
J_{b} & =\rho \int_{0}^{b_{j}} v^{2} d b_{j} \\
& =\frac{h p_{s j}}{1+\sin \beta}\left\{1-e^{-2 b_{j}(1+\sin \beta / h)}\right\}
\end{aligned}
$$

（7）式に代入して $v_{\infty} / v_{b}=1$ とおけば，よく知られて いる指数理論によるつぎの底面圧力の式を得る.

$$
p_{B b}=\eta_{J} p_{t j}\left\{1-e^{-2 b_{j}(1+\sin \beta) / h}\right\}
$$

長さの笚位に $b_{j}$ を，压力のそれに $p_{t j}$ をとれば（9） 式は無次元化さ机て

$$
\bar{p}_{B b}=\eta_{x}\left\{1-e^{-2(1+\sin \beta) / \bar{h}}\right\}
$$

ジェット効率 $\eta_{コ}$ は，ジェットの総王損失によるもの と考え，その総圧損失がノズル出口の平均動圧に比例 するすのと仮定する，指数理諭化よる平均動圧 $q$ は， $J_{b}=2 q b_{i}$ であるから

$$
q=\frac{h p_{i j}}{2 b_{j}(1+\sin \beta)}\left\{1-e^{-2 b_{j}(1+\sin \beta) / \bar{h}}\right\}
$$

そこで損失係数らを用いてクJはつぎのように書ける。

$$
\begin{aligned}
\eta_{J} & =1-\zeta q / p_{t j} \\
& =1-\left(\frac{\zeta}{2} \frac{\bar{h}}{1+\sin \beta}\right)\left\{1-e^{-2(1+\sin \beta) / \bar{h}}\right\}
\end{aligned}
$$

こてでらは実験的に求めるととにする.レイノルズ 数,ノズル傾角などによって異なるもの之思われる が，本実験においては $\zeta=0.22$ 程度である(第 3 図参 照).

（2）降下状態 GEM が降下運動を行なっている 場合、ジェット・カーテンにより下面に封じ込められ た空気は，GEM の降下に伴い第 1 図(2)のようにシ エット・カーテンの下侧を，地面にそって流出するす のと考えられる.とれがいわゆるアンダフェッド状態 である.

第 1 図(2)に扔いて水平方向の運動量流れの钧り合 いから

$$
h p_{B_{u}}=\eta_{J_{1}}\left(J_{u} \sin \beta+J_{u_{1}}\right)+\eta_{J_{2 u}} J_{u_{2}}
$$

$\eta_{J_{1}}$ はノズル・ジェットの効率, $\eta_{f_{2 u}}$ はジェット・カ 一テンの下例を流れ出る流れの効率である。ノズル出 ロおよび,ノズル・ジェット下流における運動量流れ は、それぞれ

$$
\begin{aligned}
& J_{u}=m_{u} v_{u} \\
& J_{u_{1}}=m_{u_{1}} v_{u_{1}}
\end{aligned}
$$

アンダフェッド状態においてあ，ノズル・ジェットに 分流を生じないから

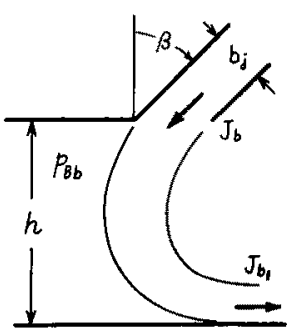

（1）平衡狀熊

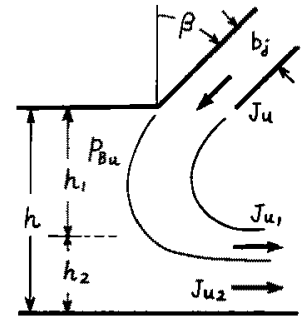

（2）降下状態

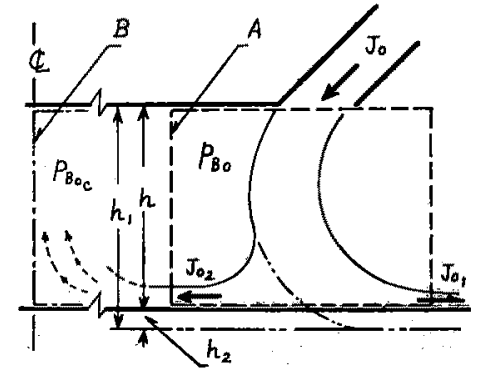

（3）上昇状態

第 1 図上下運動に伴う流れの型 


$$
m_{u_{1}}=m_{\mathrm{s}}
$$

またノズル無限下流の $v_{u_{1}}$ は

$$
v_{u_{1}}=v_{\infty}
$$

したがって

$$
J_{u_{1}}=m_{\mathrm{u}} v_{\infty}
$$

一方 GEM の降下により底面下より流出する流れに ついては，GEM の降下速度を $\dot{h}$ (降下を急) とする 之.

$$
J_{u_{2}}=-\frac{S_{B}}{l} \rho \hat{h} v_{u_{2}}
$$

との流れについてのベルヌーイの式から, $\hat{h}^{2} \ll v_{u_{2}}{ }^{2}$ 之 考えて $\dot{h}^{2}$ を省略し， $v_{u_{2}}$ を求爰方

$$
v_{u_{2}}=\sqrt{2 p_{B_{u}} \rho}
$$

これらの式を(13)式に代入すれば

$$
h p_{B u}=\eta_{J_{1}} J_{u}\left(\frac{v_{\infty}}{v_{u}}+\sin \beta\right)-\eta_{J_{2 u}} \frac{S_{B}}{l} \dot{h} \sqrt{2 \rho p_{B u}}
$$

第 1 図(2)に見るとおり，アンダフェッド状態は平衡 状態がカーテンの下側を流出する空気の流れの上に乗 ったような状態と考えられる。そとで高さんを二つの 部分 $h_{1}$ と $h_{2}$ に分け，すなわち

$$
h=h_{1}+h_{2}
$$

とし，(21)式の右辺第 1 項と $h_{1} p_{B u}$ が，また第 2 項之 $h_{2} p_{B u}$ がそれぞれ釣り合うように $h_{1}, h_{2}$ を選べば

$$
\begin{aligned}
& h_{1} p_{B_{u}}=\eta_{J_{1}} J_{u}\left(\frac{v_{\infty}}{v_{u}}+\sin \beta\right) \\
& h_{2} p_{B_{u}}=-\eta_{J_{2}} \frac{S_{B}}{l} \dot{h} \sqrt{2 \rho p_{B_{u}}}
\end{aligned}
$$

(23)式の形は,まったく(7)式と同形であって, 浮上 高 $h_{1}$ の場合の平衡状態の式となる. したがって $J_{u}$ の 值す（8)式において $h=h_{1}$ とおけばよく，さらに無 次元化ずてとにより次式を得る.

$$
\bar{p}_{B_{u}}=\eta_{J_{1}}\left\{1-e^{-2(1+\sin \beta) / \bar{h}_{1}}\right\}
$$

$\eta_{J_{1}}$ (12)式において $h=h_{1}$ とおき

$$
\eta_{J_{1}}=1-\left(\frac{\zeta}{2} \frac{\bar{h}_{1}}{1+\sin \beta}\right)\left\{1-e^{-2(1+\sin \beta) / \overline{h_{1}}}\right\}
$$

また（24)式も無次元化すると

$$
\bar{h}_{2}=-2 \eta_{J_{24}} \frac{S_{B}}{S_{j}} \frac{\overline{\dot{h}}}{\sqrt{\bar{p}_{B_{u}}}}
$$

$\eta_{J_{2 u}}$ は後に示すように， $\eta_{J_{2 u}}=1$ とすれば実験結果と 上く一致する. (25)，(26)，(27)式と(22)式加ら降下中 の GEM $の \bar{h}, \ddot{h}$ と $\bar{P}_{\text {Bu }}$ の関係求めればよく, 直接 に閉じた形では表わせないが，内㧴法または遂次近优 法により，比较的䇠算に計算できる.

（3）上昇状態 GEMが上昇する場合，ジェット・ カーテン内に封し込められていた空気容積は次第に増
大するので、これを他から補わなければならない。 れにはジェット・カーテンの一部があてられるあのと 考えられ，その結果第1図(3)のようにジェット・カ ーテンは二つに分割されて流れるととになる、これが オーバフェッド状態である.

第 1 図( 3 )に和いて，検査面を $A$ のようにとれば， 水平方向の運動量流れの釣り合いから

$$
h p_{B_{0}}=\eta_{J_{1}}\left(J_{0} \sin \beta+J_{0_{2}}\right)-\eta_{J_{20}} J_{0_{2}}
$$

$\eta_{J_{20}}$ はノズル・シェットより底面下八分流されるシェ ットの効率である.

一力検查面をBのように GEM の中心の対称面まで 延長して考えれば，対称面上ではノズルから分流され て流入してきた流れの水平速度は０となる．したが て水平方向の運動量流れの釣り合いは，中心部の $P_{B_{0}}$ を $p_{B_{0} \varepsilon}$ で表わせ价

$$
h p_{B_{0} c}=\eta_{J_{1}}\left(J_{0} \sin \beta+J_{0_{1}}\right)
$$

これは(28)式において $\eta_{J_{20}}=0$ とおいたのと型式的に 同じ式である.

また検查面をノズルに近つけてとれば，底面下へ流 入する流れは速度をすつから(28)式の第2 項は。上は

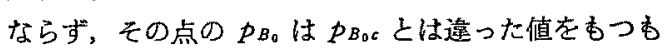
のと考元られる。したがって(28)式において，底面の 位置に応じた $\eta_{520}$ を0から適当な值までの間に選へ ばよい，これめ下は(28)式により展開するととにす る.

ジェットの運動量流れは，ノズルの出口およびジェ ット・ノズルの外方下流において，それぞれ

$$
\begin{aligned}
& J_{0}=m_{0} v_{0} \\
& J_{0_{1}}=m_{0_{1}} v_{0_{1}}
\end{aligned}
$$

ノズル外方哭限下流の $v_{0_{1}}$ は

$$
v_{0_{1}}=v_{\infty}
$$

ただしオーバフェッド状態では，ジェット流れは分流 されるため $m_{0} \neq m_{0_{1}}$ である.

底面下へ分流される流れについては，ノズル・ジェ ット内の総正 $p_{t j}$ で压力 $p_{B_{0}}$ の底面下八喷出するす のと考え， $h$ は $v_{0_{2}}$ に比べて小さとして $\dot{h}^{2}$ の項を省 格すれば

$$
\begin{gathered}
\frac{1}{2} \rho v_{0_{2}}{ }^{2}=p_{i j}-p_{B_{0}} \\
\therefore \quad v_{0_{2}}=\sqrt{\frac{2}{\rho}\left(p_{i j}-p_{B_{0}}\right)}
\end{gathered}
$$

GM 底面に分流される流量 $m_{0_{2}}$ は, 単位周長につ いて，底面積 $S_{B}$ とての上暑速度 $\dot{h}$ 加ら $\rho h S_{B} / l$ とな り, $J_{0_{2}}$ は $m_{0_{2}} \nu_{0_{2}}$ であるから

$$
J_{0_{2}}=\frac{S_{B}}{l} \dot{h} \sqrt{2 \rho\left(p_{t j}-p_{B_{i}}\right)}
$$

$m_{0}$ が $m_{0_{1}}$ 亡 $m_{0_{2}}$ に分流されるから 


$$
m_{0}=m_{0_{1}}+m_{0_{2}}
$$

(28)式に(30)以下(35)式を代入して整理すれば，

$$
\begin{aligned}
& h p_{B_{0}}=\eta_{J_{1}} J_{0}\left(\frac{v_{\infty}}{v_{0}}+\sin \beta\right) \\
& -\frac{S_{B}}{l} \dot{h} \sqrt{2 \rho p_{t j}}\left\{\eta_{J_{1}}+\eta_{J_{20}} \sqrt{1-\left(p_{B_{0}} / p_{t j}\right)}\right\}
\end{aligned}
$$

さきに降下状態に招いて，アンダフェット状態をて れ之等価な $p_{B}$ をるつ高さ $h_{1}$ の平衡状態に挔きが を行なった. 今回のオーバフェッド状態においても 同様に考え， $h$ を $h_{1}$ と $h_{2}$ に分けて，右辺第 1 項亡 $h_{1} p_{B_{0}}$ が，第 2 項と $h_{2} p_{B_{0}}$ がそれぞれ釣り合うように $h_{1}$ と $h_{2}$ を選ぶと

$$
\begin{aligned}
& h_{1} P_{B_{0}}=\eta_{J_{1}} J_{0}\left(\frac{v_{\infty}}{v_{0}}+\sin \beta\right) \\
& h_{2} p_{B 0}=-\frac{S_{B}}{l} \dot{h} \sqrt{2 \rho p_{t j}} \\
& \quad \times\left\{\eta_{J_{1}}+\eta_{J_{20}} \sqrt{1-\left(p_{B_{0}} / p_{t j}\right)}\right\}
\end{aligned}
$$

ただし $h_{2}$ の值は負であると考える。

(37)式の $J_{0}$ には，降下状態の場合之同様に（8)式 において $h=h_{1}$ 亡㧅いた式を代入し，さらにこれを 無次元化すれば,

$$
\bar{p}_{B 0}=\eta_{J_{1}}\left\{1-e^{-2(1+\sin \beta) / \overline{h_{1}}}\right\}
$$

(38)式も同様に無次元化して

$$
\vec{h}_{2}=-2 \frac{S_{B}}{S_{j}} \frac{\overline{\dot{h}}}{\bar{p}_{B_{0}}}\left(\eta_{J_{1}}+\eta_{J_{z 0}} V \overline{1-\bar{p}_{B_{0}}}\right)
$$

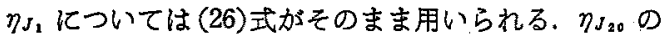
適当な值については後述する. (22)，(26)，(39)，(40) 式加ら上昇中の GEM の $\bar{h}, \bar{h}$ と $\bar{p}_{B_{0}}$ の関䋆在, 降下 状態の場合と同様に求めることができる.

\section{4. 実験}

アンダフェッドおよびオーバフェッド状態を準静的 に実験するために，第 2 図に示すような二次元模擬装 置を用いた，装置は㒷行を $50 \mathrm{~mm}$ とした透明アクリ ル板製で，ノズル傾角を $45^{\circ}$ にとりジェットを地面板 上に噴出される，地面板は上下に高さが変更でき。 万が0から8程度まで自由に設定できる，GEM の底 面に当たる部分からは，GEM の降下または上戒速度 に相当する一様な流れを喷出または吸入できる.でき るがりり様な気流を得るために，グラス・ファイバ を $10 \mathrm{~mm}$ 角の格子ではさんだ整流格子を設けた. 底面 王力は格子下端の側蹼に，静王孔を亚べて測定した。 底面部の流量は蝶弁とスライド弁によるバイパスによ り任意に調節できる. ノズル・ジェットのレイノルズ 数は, 長さにノズル融をとった場合, 地面効果の少な いときで $2 \times 10^{4}$ 程度である。

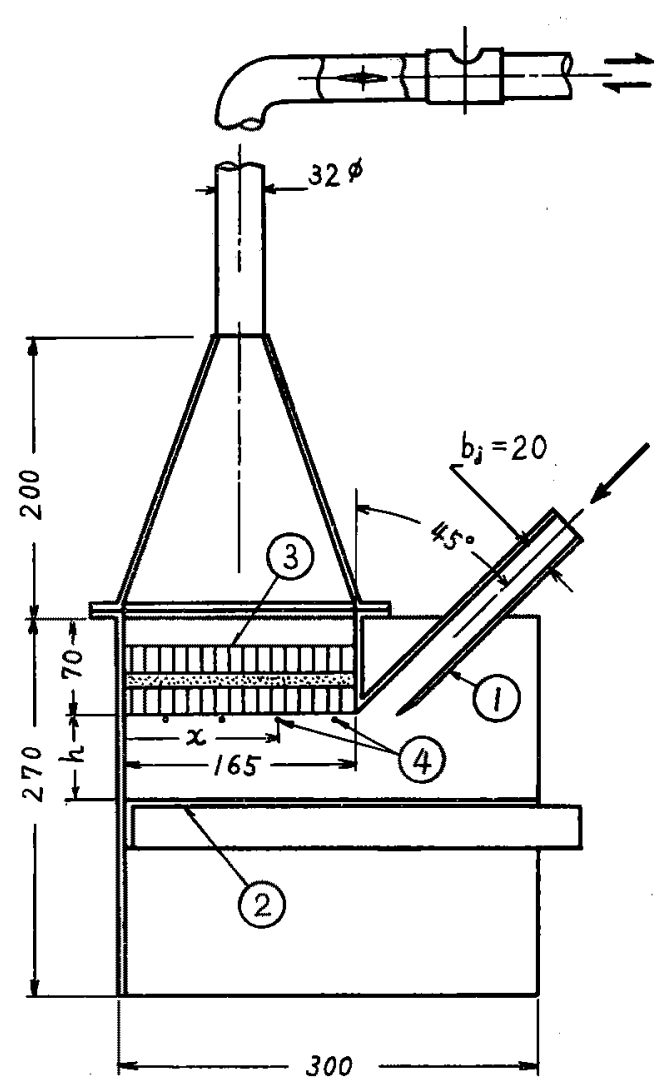

第 2 図実験装湢

(1)ノズル (2)地面板 (3)整濰格子 (4)静王孔

実験仗，設定した各浮上高について底面部への流量 を変化させ，あるいは完全に密閉して，アンダフェッ ド，オーバフェッドおよび平衡状態の流れを模擬し， このときのジェット出口の総圧，静王，底面部の流 量，底面部の静压分布を測定した。

\section{5. 実験結果および検討}

平衡状態におりる底面圧力 $\bar{p}_{B b}$ の，高さ $\bar{h} に$ 伴う 変化を第 3 図に示す. $\zeta=0.22$ にとれば, $\breve{h}=8$ 程度

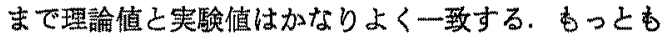
らの值はレイノルズ数，ノズル㑯角 $\beta$ などにより異な るものと思われる.

つぎにアンダフェッド，オーバフェッド状態の結果 を第 4 図，第 5 図に示す. 第 4 図は底面圧力分布の例 を， $\bar{h}=2.0$ ，末゙よ゙ 4.0 につき示したものである.丁 ンダフェッド状態では分布は大体水平であるが，オ一

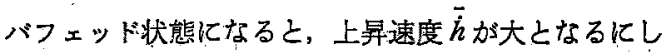
たがって，大きな届曲を生ずる。

また第 5 図は $\bar{p}_{B} の \bar{h}$ による変化を，各らおよび 4 種の底面位置 $x / b$; について示したすので, この罒加 


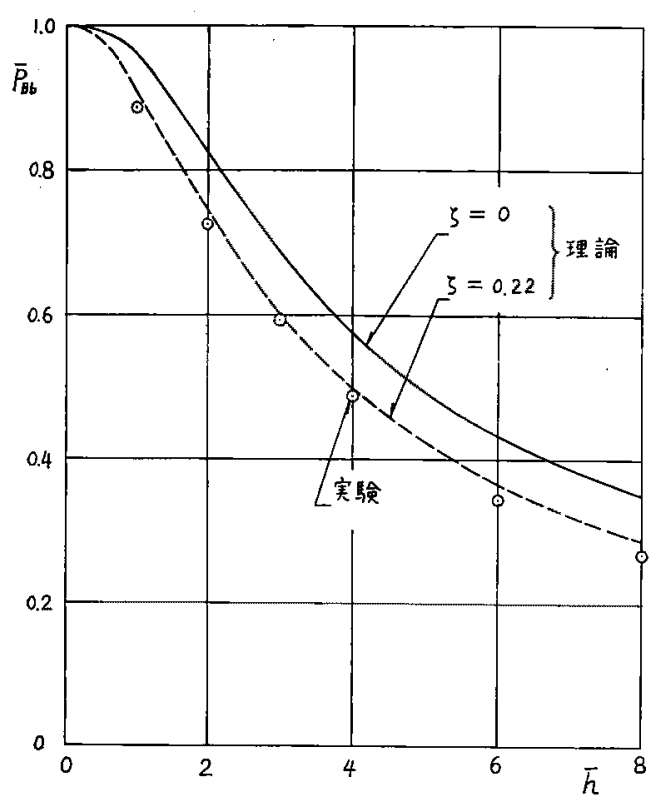

第 3 困浮上高と底面压力の関䋆（平衡状態）

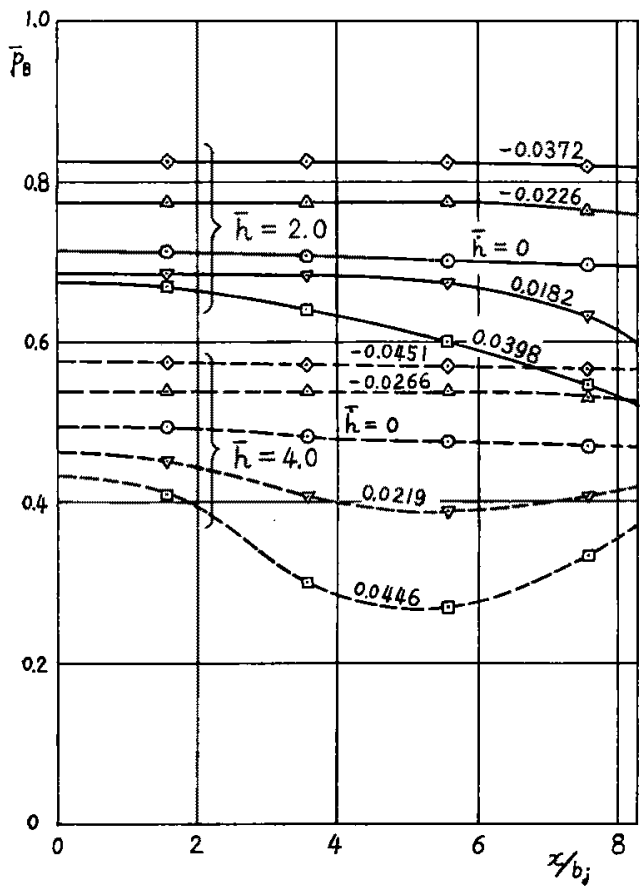

第 4 目底面圧力分布の測定例

らあ底面の圧力分布は，アンダフェッド特にはほとん ど変化がないが,オーバフェッド時には中心よりノズ ルに近つくにしたがって，大きな珐力低下を示すとと がわかる．乙の低下は礼が大きい方が相対的纪大であ る.

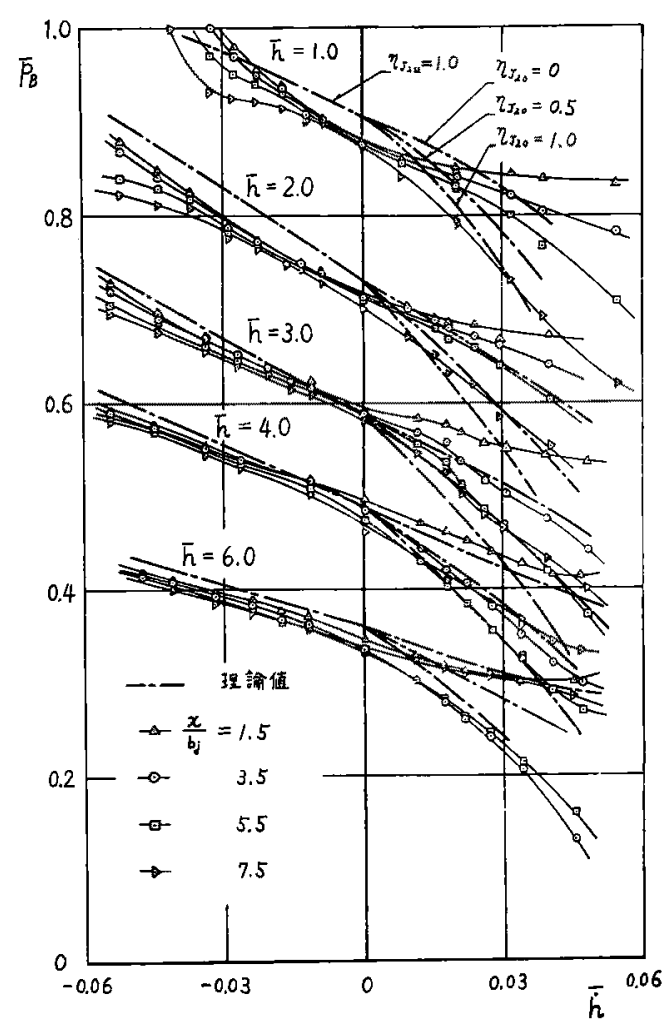

第 5 上下速度と底面压力の関係

第 5 図には理論值む記入した，アンダフェッド側

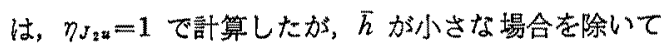
実験值とかなりよく一致する。一方オーバフェッド 側では $\eta_{J_{20}}=1.0,0.5,0$ の三種について計算し記入 した. $\eta_{J_{20}}=1.0$ のときはノズル付近の傾向に近く， $\eta_{J_{20}}=0$ のときは GEM の中心付近の傾向に近つく. これは上界状態の基脴式についてのべたように，検査 面のより方による底面圧力の違いに，上く対応してい る.

ただノズル付近ではジェットに誘起される渦がある あのと思われ，このための圧力低下もあるので, 問題 はもっと複雑であるととが予想される.しかしながら オーバフェッド時に扔いてあ，育があまり大きくな い範囲では $\eta_{J_{20}}=0$ として中心部の $\bar{p}_{B a c}$ を求め, ， ズルに近い部分の圧力低下は，むしろ主として渦の影 響によるものとして，若干の修正を加えた方が実用上 はよいのではないかと考える。

\section{6. 結 言}

GEM の上下運動時の底面圧力を求める理論式を導 き実験と比較した結果，少なくとも準静的には比较的 よい一致を見ることができた．上下運動があまり速く ない範囲では，乙の理論により底面圧力の変化につい 
て一応の推定ができるものと考える。

\section{参考文献}

1) Turus, M.P.: On the Vertical Motions of Edge Jet Vehicles, Symposium on Ground Effect Phenomena (Princeton University Press, Princeton, N. J., 1959).

2) EAMES, M.C.: Basic Principles of the Stability of Peripheral Jet Ground Effect Machines, IAS 29 th Annual
Meeting, Jan. 1961, IAS Paper No. 61-71.

3) Dukzs, T. A. \& Hargraves, C. R. : Stability Augmentation of Ground Effect Machine, Princeton University Instrumentation and Control Laboratory Report No. 601 April 1962.

4) Stanton jones, R.: Some Design Problems of Hovercraft, IAS 29 th Annual Meeting, Jan. 1961, IAS Paper No. 6145.

\section{周 辺噴 流型 GEM の 縦安定 特 性*}

\section{前田弘**}

\section{Pitching Characteristics of Peripheral Jet Ground Effect Machines}

Hiroshi MAEDA

\begin{abstract}
A theory of the pitching characteristics is presented for three-dimensional peripheral jet ground effect machines which are equipped with a compartment partition along the pitch axis. The analysis is separated into two parts, i. e. the longitudinal static stability and the dynamic pitching motion. In both cases, the behaviors of jet are quantitatively treated as the underfed and overfed operation.

At the static pitch condition, the cushion pressures in the falling downward and rising upward compartments are first discussed, and, applying those results, the simple expression of the static moment about the pitch axis is derived. Furthermore, utilizing the quasi-static principle, a second order nonlinear differential equation is obtained as the equation of pitching motion.

Detailed calculations have been carried out for a circular model GEM, and the comparisons with experimental data are encouraging.
\end{abstract}

\section{1. まえがき}

周辺喷流型 GEM のピッチおよびロールの安定性の 問題は，高速の乗物としての GEM の運動性の重要な 基礎特性の 1 つとして最近しばしば研究課題に取り上 げられている1つ-4). しかし，GEM が傾斜すると，艇 体下部の喷流はその対称性または 2 次元性を失ってし まうので，その解析は 3 次元の GEM について行なう 必要があり，その上現象がかなり複雑なため現在の上 ころまだその静安定または運動方程式などの簡単な表 示式は得られていない，筆者はさきに 3 次元 GEM の 上下運動について解析を行ない5．その結果を実験デ

* 昭和 42 年 10 月 3 日原䨂受理

** 京都大学工学部
一タと比較したところよい一致を見たので，こてでは 再び同样圭流れを仮定してての縦安定の問題の解析を 試みた。

周知のように，周辺喷流型 GEMのピッチまたは口 一ルの静安定特性は一般に不安定または僅加に安定で あってそのままでは実用上不満足であるので，適当な 安定性を与えるために艇体下部に安定ジェット（stability jet)または仕切り板(compartment partition)を 設けるのが普通である. 安定ジェットおよび仕切り板 の勃果はいずれあ艇体が傾斜したとき回転軸に対して 下降した領域と上昇した領域の間に生ずるクッション 压力差加混合しないまま一定に保たれる作用を有し， ての圧力差によって復元モーメントを得ようとする方 法である. 最近は構造的に簡単で効果の上い仕切り板 が多く採用されていのて，ここです仕切板のみを取り 付けた GEMについて取り扱う.

計算に当たっては簡単のために，つぎの仮定を行な j.

（1）ピッチ角の変化によってホバー高さは変化し ない.

（2）前進速度は０上する。

（3） GEM 底面にピッチ軸汇沿って仕切り板を取 り付け, 前後の圧力差は任意の值で一定に保たれるも のとする。

（4）流れの解析には単純運動量理論（simple momentum theory）を用いる.

（5）噴流の運勳量はピッチ角によって変化しな (.

（6）空気の非圧縮性の条件は常に満足される.

（7）空気の粘性に上る勃果は考虑しない。

本解析は 2 部に分かれていて，第 1 部ではピッチ軸 